\title{
LA ESTILÍSTICA REDIVIVA: LA SEMIOESTILÍSTICA Y LOS SIGNOS POÉTICOS
}

\section{Ileana Oancea}

\author{
Universidad del Oeste (Timișoara)
}

Se ha hablado de la muerte de la estilística en pleno proceso de afirmación de una semiótica autotélica. Interesada en las estructuras significantes, que funcionan «in vitro», rotas, según la tradición saussuriana, de cualquier condicionamiento, la estilística era anulada por la dimensión constitutiva de los fenómenos del lenguaje que tenía la obligación de investigar: la subjetividad. «El error de la intencionalidad» era la severa sanción que amenazaba cualquier tentativa de acceder al territorio fluctuante de la interioridad.

Últimamente, después de hablar de la muerte de la estilística, podemos observar una especie de hegemonía suya, directa, por medio de la repetición de algunos de los temas fundamentales de la teoría estilística, y también indirecta, por medio de las nuevas conexiones que la estilística realiza hoy. Paradójicamente incluso, la subjetividad invade, como núcleo problemático, la semiótica misma, tan intransigente, 
hasta hace poco, en cuanto a la penetración en el campo de interés de las ciencias antropológicas de lo que es móvil, difícil de captar.

Se dice hoy, de manera explícita, que «Chassez le style par la porte, il revient par la fenêtre» (Pavel, 1997; Larthomas, 1998; Molinié, 1998). Sólo que estas ventanas habían sido antes abiertas de par en par, y la vuelta de la estilística al centro de la atención representa el resultado natural de un cambio de naturaleza epistemológica.

La posmodernidad es relativista, multi-relacional, multiplicando los puntos de inserción del «conocimiento». «Il pensiero debole», para emplear el concepto de Vattimo, característico del epistema actual, deja lugar a la firmeza del cerrar en horizontes faltos de ambigüedad.

Manteniendo la nostalgia cientificista, esta «estilística rediviva» se instala en el centro fascinante de la subjetividad asumida por la nueva racionalidad de «il pensiero debole». La vuelta de la estilística se hace bajo la luz débil de un conocimiento vacilante, en busca de zonas de estabilidad.

En realidad, esta vuelta es más que una vuelta. Puede representar una manera de ser del conocimiento postmoderno. La estilística es hoy una semiótica que ha ganado su derecho de estudiar la tercera relación del proceso semiótico: la relación entre signos y utilizadores. Dicho de otra manera, la estilística actual es una semioestilística. La estilística es al mismo tiempo una dimensión de la hermenéutica o la hermenéutica es la hipóstasis mayor de una estilística generalizada; la estilística opera como un savoir faire en el espacio de la literatura comparada y de la historia literaria tradicional.

Por otra parte, generalizando, observamos que el nuevo dispositivo cognitivo tiene de hecho como preocupación esencial la antigua problemática del estilo y de la subjetividad y por eso, la estilística reafirma, quizá más que nunca, la fuerza interrogativa. En las épocas de triunfo del racionalismo cartesiano ha introducido las sombras y los dilemas de otro tipo de conocimiento, todavía subversivo. Hoy asume los horizontes de este nuevo conocimiento: relativista, no-acabado, lanzando puentes hacia un pasado en el que reencontramos, en tantas hipóstasis, la intranquilidad del espíritu creador del hombre.

Siguiendo la evolución de la estilística moderna podemos descubrir precisamente este movimiento de cerrar-abrir: el cerrar del estructuralismo y poco después el abrir post-estructuralista de la postmodernidad. 
Es en la estilística española y concretamente en Dámaso Alonso, donde encontramos, anterior al movimiento europeo que va a intentar franquear los límites impuestos por F. de Saussure a través de su Cours de linguistique générale, los signos de la nueva estilística liberada de la autarquía estructuralista. Dámaso Alonso, en un famoso libro, se sitúa explícitamente más allá de la posición de Saussure. Y lo hace justo en el punto neurálgico de la doctrina de Saussure: el signo lingüístico y su carácter arbitrario. El signo lingüístico resulta no responder a este postulado fundamental de la semiótica en la poesía, cuyo funcionamiento semiótico tiende a la realización de la motivación entre significado y significante. Es la tesis fundamental sobre la cual se forma la exégesis del libro de Dámaso Alonso, Poesía española. Ensayo de métodos y limites estilísticos (1971) cuyo refinamiento analítico es inigualable: «La última diferencia con la teoría de Saussure - afirma Dámaso Alonso- es, aunque consecuencia de las anteriores, la de un enunciado más radical; para Saussure, el signo, es decir la vinculación entre significante y significado, es siempre arbitrario. Pues bien: para nosotros, en poesía, hay siempre una vinculación motivada entre significante y significado. Esto es precisamente nuestro axioma inicial. En él entendemos poesía en el sentido general del alemán Dichtung; pero podemos añadir, que la motivación del vínculo entre significante y significado es aún mucho más patente en la poesía en verso, sobre todo en la lírica o en la narrativa teñida de fuerte matiz lírico» (1971: 31-32).

Se abre de esta manera ante la investigación un territorio difícil de indagar: el del lenguaje lírico, lenguaje por excelencia de la relación subjetiva. La semiótica de Saussure del Cours de linguistique générale abre paso a la semiótica del segundo Saussure ${ }^{1}$ de los estudios dedicados a los anagramas (Starobinsky, 1974). Saussure contra Saussure produce un espacio, recuperado por la estilística. De esta manera aparece la nueva alianza entre la estilística y la semiótica, vista como teoría y método de otro tipo de semiosis, la poética, lo que ha generado cierto tipo de ars interpretandi. Es una característica importante de la estilística española que fundamentó, sin nombrarla así, una semioesti-

${ }^{1}$ El mismo F. de Saussure, en las laboriosas investigaciones dedicadas a los anagramas, llega a algunas ideas que perturban la visión sobre la transparencia del signo linguiístico expresada en el Cours de lingustique générale. Publicadas por Jean Starobinsky, Les mots sous les mots. Les anagrammes de Ferdinand de Saussure (Paris: Gallimard, 1974) han sido consideradas una segunda revolución copernicana en la lingüística. Completan el conocimiento del lenguaje-comunicación lógico-referencial del Cours con una tentativa de conocimiento, sobre las mismas bases semióticas, del lenguaje poético, cuya motivación «anagramática» ha perseguido con asiduidad. 
lística que ha representado una brillante contra-ponderación ante algunos excesos formalizantes de la estilística francesa.

De este modo, la poesía ha sido el terreno predilecto de una estilística que ha «re-humanizado» la ciencia de la lengua después de lo sucedido de Saussure. En este sector la estilística ha registrado también los mayores éxitos. Y es normal que sea así, la poesía siendo por definición el asumir subjetivo del lenguaje por parte del creador, al nivel más alto. El lenguaje lírico es la modalidad más aguda de existencia de aquel $i l$ pensiero debole tematizado por el pensamiento contemporáneo.

Retomando de la semiótica de Saussure el término de signo, como lo hemos visto en el caso de Dámaso Alonso, la estilística puede operar una serie de matizaciones esenciales que le permiten el enriquecimiento del conocimiento de la creatividad linguiística, la poesía siendo por excelencia creación de significado por medio de la lengua. Por eso, la estilística se confronta con los problemas de una semiosis ilimitada, específica sobre todo de la lírica moderna, de la instauración de lo real a través del lenguaje en el texto poético y de la transformación de los signos lingüísticos en signos poéticos. La estilística en su hipóstasis de semioestilística tiene, de este modo, también una naturaleza teórica. A continuación nos vamos a detener en este aspecto.

Como se ha afirmado con frecuencia, el lenguaje representa la forma más alta de una facultad inherente de la condición humana, la de simbolizar, es decir, de representar lo real por medio de un signo. Semejante sistema de símbolos como lo es la lengua revela un dato esencial de la condición humana: no hay relaciones de conocimiento inmediatas y directas entre el ser humano y el mundo, y tampoco entre ser humano y ser humano.

Volvamos a la doctrina de Saussure para delimitar el espacio de la semio-estilística. Al situar la noción de signo en el horizonte de la ciencia y de la filosofía actual, F. de Saussure ha contribuido a la constitución de una semiología general.

Según Saussure, repetimos, el signo lingüístico que representa la base del fenómeno de comunicación, hacia el cual se dirigía su interés que parecía exclusivo hasta la publicación también póstuma, pero más tardía, de las investigaciones de los anagramas, es la entidad fundamental - y la única con este grado de generalidad - de la ciencia del lenguaje. El signo lingüístico es una unidad bilateral (con doble entrada) entre una imagen acústica (el lado directamente asequible al conocimiento linguíístico) y un concepto (la cara impalpable, de natu- 
raleza intelectual, conceptual del signo). Entre ellos hay una relación arbitraria, no-motivada. El plano ontológico (el designado o el referente hacia el cual se envían los signos a la lengua) no pertenece a la lingüística como ciencia autónoma, la lengua siendo según él, forma, no sustancia. El peldaño más alto de la linguiística de Saussure es la frase, como conjunto organizado de signos lingüísticos.

Si tenemos en cuenta, sin embargo, que el lenguaje tiene una doble naturaleza, que no es sólo un hecho de comunicación estrictamente referencial, sino también material del arte más sutil, que es la poesía, comunicación que implica un máximo de subjetividad, el signo lingüístico de Saussure concebido para cubrir sólo la dimensión referencial del lenguaje, necesita ser doblado por otra entidad correspondiente a su segunda esencia. Éste es el signo poético (estético o estilístico) que se tiene que delimitar del lingüístico. Dámaso Alonso no opera a nivel terminológico esta delimitación, pero la exégesis completa se fundamenta en esta distinción.

Se ha hablado de los valores connotativos del signo lingüístico en poesía. En realidad tenemos dos hipóstasis semióticas del lenguaje y por consiguiente dos tipos de signos como unidades mínimas de significación. Los signos poéticos tienen una existencia propia, aunque provengan de los signos linguísticos. La obligación elemental de la poesía es trascender los signos convencionales de la lengua, hacia aquellos dotados de función estética. La instauración y la perceptibilidad de la diferencia entre ellos constituyen el trabajo semiótico alrededor del cual se configura.

Esta dualidad fue observada por el científico rumano Dumitru Caracostea hace unos decenios. Demostrando un pensamiento moderno, de esencia semiótica, antes de su imposición europea, hizo esta distinción al nivel de los signos mínimos de la comunicación, es decir, en el punto de encuentro entre la estilística y la semiótica. Define como estemas (Oancea, 1988; Munteanu, 1972) los signos expresivos de la intuición, del afecto y de la fantasía, que proporcionan cierta relación con el mundo y cierto tipo de conocerlo, de una manera diferente a la denotativa, conceptual, de la tradición «clásica» de Saussure .

Esta delimitación representa un momento muy importante para la estilística rumana e implícitamente para la estilística europea, momento por mucho tiempo desconocido y marginado desde el punto de vista de su relevancia teórica. En la cultura española, poco más tarde, Dámaso Alonso, partiendo explícitamente de Saussure, pone en tela de juicio la concepción cerrada de Saussure acerca de la significación, 
postulando un modo diferente de funcionamiento de la lengua en la poesía, aspecto éste poco valorado desde el punto de vista de su contribución a la teoría semiótica. La reconstrucción de la estilística se hace, pues, partiendo de una referencia polémica al pensamiento de Saussure y a sus ideas sobre el carácter arbitrario del signo linguístico.

Esta forma de ser del signo lingüístico en poesía nos da derecho a postular la dicotomía signo linguiístico/signo poético. Todas las características definitorias del signo lingüístico se organizan dentro del poético, que no es solamente otra hipóstasis del signo lingüístico, tal y como se ha considerado en muchas ocasiones, sino un signo con un perfil semiótico específico.

La estructuración diferente de los signos de la lengua, derivando de su distinta manera de funcionamiento semiótico, implica la necesidad de una disociación al nivel de la lingüística misma. G. Mounin reconocía en Les problèmes théoriques de la traduction que entre la función comunicativa y la función estética del lenguaje hay «une coupure assez profonde» (Dufrenne, 1975).

La poesía es un fenómeno semiótico de tipo especial y los signos poéticos que la hacen posible como lenguaje en el lenguaje se desprenden, por su finalidad comunicativo-estética, de los lingüísticos y se integran entre los signos icónicos, análogos. Desde este punto de vista, la inclusión de la lingüística en la estética (con la mención muy importante que se trata de esta lingüística con esencia propia) pensada por Croce y Vossler, lo que, actualizando, corresponde a la afiliación del estudio del lenguaje poético a la esfera más amplia de la semiología de las artes, no parece sin fundamento.

El problema no es si la estilística literaria está dentro o fuera de la lingüística. Es otra lingüística, teniendo un contacto natural con las ciencias teóricas sobre literatura y arte. Ciencia de la literaridad, por tanto de la tipología y de las categorías de la literatura en último lugar, tiene que ver con el carácter de unicidad de la relación sígnica en el texto poético.

La poesía propone para decorar universos imaginarios particulares, mundos posibles válidos hic et nunc, en los cuales la significación está contenida en las relaciones complejas y móviles que los signos inician a nivel intratextual y, sobre todo, en las experiencias innovadoras, a nivel intertextual, en función de una conciencia valorizadora. La significación poética es la expresión de este dinamismo textual que propone una coherencia profunda, más fácil o más difícil de construir. Hallada por medio 
de la lectura, esta coherencia fija el proceso mismo que la produjo, es decir, cierta trayectoria interpretativa, una opción semántico-funcional fundamental. De manera fatalmente reductora, inmovilización provisional de la movilidad semiótica constitutiva del texto, este significado totalizador profundo no agota la capacidad de significación.

La provocación que la poesía dirige a la interpretación es una provocación continua. Y esto pasa porque los signos poéticos tienen un carácter sintagmático, combinatorio, más o menos «abierto» y por lo tanto se pueden re-definir en función de las redes isotópicas en las cuales se ven entrenados. Ello plantea el difícil problema de la «entrada» analítica en el texto, especialmente importante en la poesía moderna, concebida con lucidez como procesualidad textual. Y también hace que la lingüística de la lengua de Saussure dé paso a una lingüística del discurso, el espacio de una profunda reconversión semiótica, la de los signos lingüísticos en signos poéticos. $\mathrm{Y}$ de esta manera unos son lo que no son los otros, según el principio de Saussure de que en la lengua sólo hay diferencias; las diferencias aquí son de naturaleza semiótica y dependen del tipo de comunicación que se instituye y del tipo de semiosis, siendo el poético el que nos interesa aquí.

Por lo tanto el estudio dicotómico del lenguaje: lengua/habla; sincroníaldiacronía; lingüística internallingüística externa se completa con añadir la dualidad signo lingüístico/signo modo de construcción estilístico, poético; lingüística de la palabrallingüística del texto.

El signo poético tiene cierto tipo de sustancia que le falta, en general, al lingüístico. Esta sustanciación instituye la significación y es el fenómeno decisivo de la comunicación poética. Los mundos imaginarios que la poesía nos propone para contemplar hablan de cosas sorprendentes, que nos llegan muy dentro y que comprendemos mirando el modo de construcción poemática que se realiza por la infusión de materialidad.

De alguna manera, el fenómeno es observado por Dámaso Alonso a lo largo de la investigación de la poesía española y es considerado constituyente de la poeticidad. Vamos a observar este fenómeno vital para la constitución y el funcionamiento de los signos poéticos, sobre todo en la poesía moderna.

Al nivel del significante, la sustanciación es absoluta, es decir, parte de cero, el signo lingüístico siendo, se sabe, en general arbitrario. Al nivel del significado, aparece un aumento de la sustancialidad que éste tiene, a veces, al margen de o en contradicción con el plano referencial: sutil convocación de los elementos de lo real, para nombrar 
una simil-realidad, realidad ficticia que comunica, figurando una relación subjetiva con lo existencial.

Si la lengua, entendida desde la perspectiva de Saussure (el lenguaje de la comunicación social), es forma, no sustancia, el lenguaje poético incorpora la sustancia de tal manera que el soporte formal (el significante), por sus cualidades acústicas, ignoradas en el signo lingüístico, colabora «miméticamente» con el plano del contenido (el significado). El tejido poético exhibe detalles de la sustancia sonora para atribuirles significado. Tocando lo más intimo de la significación, esta perceptibilidad de la materialidad de los sonidos (nivel, timbre, acento, duración etc.) orienta el signo convencional de la lengua hacia la materialidad de la cual ha sido extraído; la esencia semiótica de la comunicabilidad no se pierde por la delimitación de lo real, sino todo lo contrario, se fructifica como acto semiótico original e irrepetible. Realizada delante de nosotros, la delimitación de lo real es ahora obra del poema. La poesía es una semiosis perpetua, re-emprendida con cada texto y cada poeta.

Seguimos sin olvidar ciertos versos, citados por exegetas, a los cuales esta penetración del significante en el significado les otorga un encanto especial. Las armonías sonoras crean alrededor del significado un aura inefable y al mismo tiempo ayudan a imponerlo como realidad co-sustancial del nombrar. La comunicación poética nos produce la alegría de la irrupción fresca de lo real en la forma ordenada del poema. $\mathrm{Y}$ entonces, por supuesto cuanta forma logramos descubrir en la toma de posesión del mundo sensible por el poema y en su destilación en las retortas de las figuras textuales, tanto significado podemos percibir. Las figuras textuales representan la forma de entrar de la sustancia en el texto poético. Por ejemplo, este verso de Mallarmé: Solitude bleue ou blanche agonie. ¿Cuál es el referente hacia el cual nos orienta este texto? ¿Cómo imaginarnos lo inimaginable? La realización de la información poética ha contribuido seguramente a la sustanciación de la forma por la calidad acústica de los sonidos que «colaboran» con el significado y entra en el proceso de significación (alrededor del «significado» se han tejido auténticos «campos sonoros»), al igual que cierta sustanciación del contenido (se materializan los términos abstractos solitude, agonie, acompañados por determinaciones cromáticas).

Mas allá de la fuerza del tejido sonoro, estas realidades anímicas impalpables se transforman en objetos del poema y se pueden contemplar debido a que han adquirido cierta consistencia. Las palabras que se parecen desde el punto de vista del sonido, se atraen las unas a las otras por el significado, decía Jakobson. Este tipo de relaciones aparece al 
nivel de las parejas solitude bleue y blanche agonie. En el mundo puramente verbal en el que se refugia el poeta, expresar significa crear lo real dentro del lenguaje, tal y como es percibido por la conciencia. Los signos poéticos constituyen el esquema afectivo-imaginativo a través del cual el poeta «lee» el mundo a su manera, es decir le da cuerpo y lo significa al mismo tiempo.

En el verso de Mallarmé el esfuerzo del poeta por traer algo de la consistencia de lo real, con el fin de comunicar un contenido anímico, se traduce en las metáforas afectivas, las calificaciones cromáticas bleue, blanche. Difícilmente igualables por una paráfrasis, ellas imponen «pictóricamente» un régimen de subjetividad profunda. Al mismo tiempo, entrañan también la cara palpable del signo. El significante se refleja en el significado en el acto único de una semiosis ilimitada. El texto adquiere de esta manera una corriente subterránea, que instaura redes asociativas subliminales. Dado que a su vez significan, los sonidos ya no son un simple vehículo del significado. Il pensiere debole tiene un corolario lingüístico. El mundo puramente verbal instaurado por el poeta, de una materialidad irreal, visionaria, es un desafío abierto de la univocidad racional.

La «comunicación» del poeta es honda y compleja, hace resonar zonas amplias de la psique. La musicalidad del significado se añade a la figuratividad: la cromática es un medio de «materialización» difusa y de sugestión. Produce al lado de la semantización de los sonidos aquella ambigüedad de la recepción, decisiva para lograr el acto de comunicación poética. En este universo los colores y los sonidos «hablan» de un mundo de la subjetividad que no se puede transmitir, en su ambiguiedad, más que bajo la forma de materia raptada a la complejidad del contenido sustancial del mundo gracias a estos fascículos.

Los creadores han intuido la vocación intrínseca significante, e incluso de cierto tipo, de unos sonidos en el texto poético. Como ejemplo: un encuentro conmovedor. Eminescu ha valorizado el efecto «luminoso» de la vocal $a$, en un verso en el que la realidad asumida como luminosidad frenética esencializada está atrapada en el lenguaje y modelada en su materialidad analógica por la explotación del carácter abierto de esta vocal. Aquí tenemos el memorable verso, reverberando la explosión de la luz del plano del significante: Argint e pe ape si aur in aer (Plata sobre el agua y oro en el aire), precedido por el verso que «hila» de forma mágica la luz por la reiteración de la vibrante $r$ : Cînd torsul s-aude l-al vrăjilor caer (Cuando se oye el hilar de los hechizos caer). El significado argint (plata) y aur (oro) se retoma en clave mu- 
sical por la reiteración de la vocal $a$, a lo largo del verso. El significado se refleja en el significante, opaco, arbitrario, lo que hace que la sugestión musical se vuelva constitutiva de la construcción del significado. La idea de luminosidad se impone en los dos niveles del signo: por la presencia de los metales brillantes de un cromatismo ritualizado, argint y aur, y por la calidad del tejido sonoro que pone de manifiesto la presencia de la vocal $a$, percibida así en su materialidad: $a-a-a(u)-a(e)$. No estamos ante la descripción del universo, sino ante la exposición de sus reverberaciones en el régimen de las grandes correspondencias, donde la fluidez del agua y del aire encuentra la consistencia de los metales reflejando luz, una luz «hechizada», brotando del cuerpo sonoro de los dos lexemas. Por otra parte, Mallarmé había pedido a los poetas: «peindre non la chose, mais l'effet qu'elle produit» (Oancea, 1998).

Las mismas valencias «pictóricas» aparecen también en los famosos versos de Góngora, en los que «la materia» sonora se convierte en la superficie de reflexión de la luz que el significado extrae de la materialidad compleja y difusa del mundo. Encontramos de nuevo una experiencia de la luminosidad, que une más allá del tiempo, a Eminescu y a Góngora. La retomamos comentada por el gran estilista español Dámaso Alonso: «He aquí la argentería líquida que rompe en la misma falda de la montaña, cuando el pie argenta de plata al Lilibeo o la virginal blancura intacta que la Alba entre lilios cándidos deshoja» (1971: 383). La conclusión del exegeta es importante para la vocación motivadora de la poesía de siempre, no sólo de la poesía moderna: «una de las más extraordinarias características del arte de Góngora es que su verso es una constante motivación intensificada del vínculo entre significante y significado» (Alonso, 1971: 384). Porque, precisa el poeta-estilista: «Son movimientos estos de asociación de color y vocales que, como los de medida y ritmo acentual (e íntimamente asociados a ellos), tienen lugar en una cámara secreta de nuestra psique, no exactamente en la imaginación figurativa, sino como en el subsuelo de ésta o en su trasfondo.

En esa danza hay un verso, el segundo,

la Alba entre lirios cándidos deshoja, en el que la musicalidad parece haberse concentrado, vestida de colores albeantes. Prescindiendo de dos relajadas finales (-os), todo el verso, salvo la última tónica, es un delicioso ondear de vocales claras:

$a-a-e-e-i-i-o-a-i-o-e-o-a »$.

(Alonso, 1971: 381). 
Eminescu se encuentra con Góngora, un encuentro esencial, en el acto, cada vez único, de conversión de los signos lingüísticos en signos poéticos. Está claro que la motivación se la induce el significado al significante, pero parece que los sonidos de la lengua tienen, por sus cualidades materiales y por lo tanto perceptibles, ciertas «predisposiciones» semióticas que los poetas intuyen y, con independencia de una lengua concreta, las hacen vibrar en tonalidades parecidas. Leer poesía significa dejarse invadir por las características sensibles de un universo de signos que aspiran a la concreción y la fuerza de lo real.

Gracias a esta motivación buscada y provocada por el poeta, el signo cobra una materialidad que, por medio de la sinestesia auditivo-visual, se funde en una nueva representación, compleja, imposible de racionalizar el concepto de manera unívoca por paráfrasis, volviendo a ser intuición. Y la intuición existe, como lo ha demostrado Croce, como expresión y en la expresión. Sin embargo, la semejanza que se realiza ahora no se establece entre palabra y referente, sino, como bien se sabe, entre lo que suscita en nosotros la palabra y lo que suscita la cosa, lo que confiere al signo apertura o, según Tudor Vianu, que se refería a la metáfora simbólica, materialización ejemplar de este tipo de signos, su carácter ilimitado (Vianu, 1957). La ambigüedad sustancial del mundo y de su percepción subjetiva vuelve ambigua la sustancia del Verbo. El mundo es dicho por el poeta que espera que el enigma mismo de la intuición individual del mundo se repita en la vida palpitante de la poesía.

El lenguaje artístico deja de ser instrumento pasivo de la expresión que constata, sino que se convierte en activo, parece cargarse de electricidad y de expresión de la convención pasa a ser invención, creatividad. El lenguaje poético, y especialmente el lenguaje poético moderno, plenamente consciente de la ambigüedad que le da forma, representa el doblegamiento de la estructura de la lengua a la calidad de la experiencia subjetiva, que se realiza, en los momentos brillantes de la creación, en las dos vertientes del signo.

Como en el caso del lenguaje-comunicación, en el del lenguaje poético estamos ante un proceso de denominación; pero, si en el caso de la lengua denotativa, este proceso está fuertemente anclado en la diacronía, el esfuerzo de denominación tiene lugar en el lenguaje poético cada vez que se cumple el acto artístico. Al verse el poeta obligado a dar cada vez otro nombre a una realidad ambigua, polivalente, profundamente subjetiva, convierte los signos lingüísticos convencionales en signos lingüísticos sustanciales, el léxico se funde en la sintaxis, el 
signo poético justificando su razón de ser sólo como elemento de la textualidad poética. Así se pasa de la estructura adquirida a la estructura recreada del lenguaje, es decir, en los términos de Humboldt, de érgon a enérgeia.

La estilística del lenguaje poético es aquella lingüística que tiene como propósito estudiar precisamente este paso de las estructuras lingüísticas referenciales a estructuras siempre abiertas a la experiencia subjetiva, teniendo como entidad específica el signo poético. El lenguaje, decía Saussure, es forma y no sustancia ${ }^{2}$. El lenguaje poético es sin embargo un lenguaje de la sustancia atraída bajo la incidencia de la forma.

Desde esta perspectiva la lengua poética ya no puede mirarse como una anomalía del lenguaje (como lo hace Jean Cohen en Structure $d u$ langage poétique), sino como el lenguaje propio, natural y necesario a la poesía, «construyendo» cada vez una realidad que contradice la percepción común y que tiende a aparecer en la lengua en su materialidad sustancial. Si, tal y como lo decía Cohen, «la parole poétique est tout à la fois mort et résurrection du langage» (Cohen, 1996: 224), entonces la lengua revela en la poesía su doble esencia no de una vez, sino por la acumulación de los signos lingüísticos y la instauración de los poéticos, completamente obra del poema. Por consiguiente, no tenemos un signo lingüístico en dos hipóstasis (la connotativa y la denotativa), sino dos signos diferentes con distintas denotaciones: la socializada y la individual, procedentes de las redes intratextuales, por tanto una significación de naturaleza contextual en la que se refleja, según la formula de J. Cohen, «la cara afectiva del mundo» (1994: 226). Un mundo abierto a una semiosis ilimitada porque refleja esta aventura subjetiva de la denominación del mundo, que ha tenido lugar en la poesía, una y otra vez, y porque este mundo ficticio espera la relación de lectura para mostrarse como es, cada vez en su unicidad irreducible, indecible de otra manera.

2 Dice Eugenio Coseriu partiendo de Saussure: «Uno de los aspectos más graves de la reducción del lenguaje a un «lenguaje» nos parece, justamente, el hecho de que ello implica que se excluya del plano de la «lengua» la muy importante, aunque a menudo ignorada, función evocativa, función que el lenguaje fónico posee sobre todo gracias a su «sustancia». Y añade: «Es erróneo si pretende significar que la "lengua"» es forma vacía, sin la atribución de la sustancialidad. Y es una convención semántica si sólo se pretende que se llame «lengua» un conjunto de formas como tales, sin referencia a los atributos sustanciales que integran las formas mismas» (Teoría del lenguaje y lingüística general, Coseriu, 1969: 204-205, 220). En este punto la contribución de Coseriu en la reelaboración de la teoría de Saussure es esencial. 
En Eminescu, el régimen nocturno de lo imaginario es dominante. La luna con todo su grupo de representaciones míticas y simbólicas es una aparición omnipresente. A veces, este lexema funciona textualmente en el espíritu anagramático de Saussure, el que ha roto la estabilidad del edificio semiótico propuesto por el Cours. La palabra induce especialmente la primera sílaba que promueve la vocal $u$ en sus cercanías, de acuerdo con el paisaje lunar ( $u$ es una vocal cerrada), como por ejemplo los versos: de iese-n luciu luna sau alunece luna. El estatuto de hipograma de este término poético fundamental nos permite entrar en el laboratorio de la poesía de Eminescu, que nos puede desvelar un trabajo semiótico inesperado y especialmente intenso, para que nos preguntemos sobre las profundas raíces de la creación de significado en la poesía.

La semiosis poética puede ser especialmente sutil, construyendo un espacio amplio de la significación que anula la linearidad de los signos linguísticos en el enunciado. $\mathrm{El}$ texto poético nos aparece como un palimpsesto o como un iceberg (Vlad, 2000) por la diseminación anagramática del significante. Al estudiar esta zona enigmática de la significación, Saussure ponía las bases de una semiótica de tipo particular, situada en contradicción con la que había postulado en el Cours de linguistique générale. Se ha dicho incluso, recientemente, que «avec les anagrammes l'auteur du Cours semble élaborer une contre-linguistique» y la ciencia de la lengua nos aparece como «irrémédiablement scindée» (Gandon, 2001: 312).

Una estructura anagramática de este tipo, extremadamente compleja e interesante, que podría confirmar las laboriosas investigaciones de F. de Saussure, aparece en la poesía de Eminescu Lebăda (El cisne), analizada por Mariana Net. Reproducimos el texto: $C a ̂ n d$

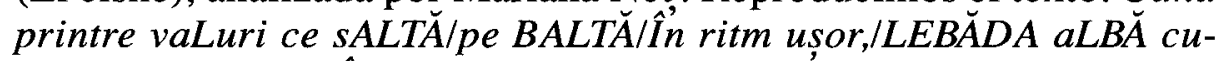
aripiLE-n vînturi/În cînturi/se Leagănă-n Dor; aripiLE-i aLBE în apa cea caLDĂ/Le scaLDĂ/din eLE BĂTÎND/și-apoi pe luciu, pe unDA D-Oglinde/le-ntinDE: $O$ barcă de vînt. El comentario pone de manifiesto, a la vez que el refinamiento del texto, el refinamiento del análisis: «A la suite des assonances, des allitérations, des élisions- en un mot, grâce à une licitation excessive du plan prosodique, le poème aboutit à une sorte de figure textuelle qui lui est propre et qui est unique chez Eminescu, qui ne paraît que dans ce texte particulier.

Il s'agit du «mot» lebădînd, une sorte de gérondif d'un verbe inexistant, caché dans le texte. 
Cette anagramme du cygne, ce fait de le cacher sous la forme de verbe sont autant de signaux que le signifié du terme cygne, ainsi que son référent dans ce texte-ci cessent d'être le terme homonyme de la langue naturelle.

Plus précisément, le cygne n'est plus «un genre d'oiseaux aquatiques plus grands que les oies, au plumage blanc ou (plus rarement) noir» (cf. DEX) (Net, 2001: 95-96).

Las palabras que están debajo de otras palabras llevan la emergencia del significado en el texto; es el descubrimiento que había preocupado a Saussure, sólo que ellas deben ser descubiertas y por eso la afirmación de Pascal es significativa: «no me habrías buscado si no me hubieras encontrado». La estructura anagramática representa una situación ejemplar - y extrema - para la semiosis poética y para el modo de existencia de los signos poéticos.

Mencionamos una de las conclusiones del análisis semiótico sobre el lenguaje de Eminescu, realizado por Mariana Neț. Nos deja descubrir a un Eminescu difícil, más allá de la imagen de un poeta transparente, que no plantea dificultades de descodificación al nivel del lenguaje: «La investigación demuestra que el lenguaje poético alcanza "el polo máximo" cuando oculta sus propias diferencias morfosintácticas, cuando la semántica parece una consecuencia directa de la fonología, diferencias modeladas prosódicamente, y las normas morfosintácticas del enunciado aparecen sólo como una convención de escritura, como una “concesión" a la lisibilidad» (Net, 2000: 135).

Se ve de esta manera que la evolución de la estilística hacia la semiótica ha aumentado considerablemente la capacidad de la estilística de investigar el lenguaje poético. En el estudio del lenguaje poético de Eminescu hay un análisis semiótico de gran refinamiento que se abre también a los problemas de teoría semiótica. Se trata del libro de Mariana Net, Eminescu, altfel. Limbajul poetic eminescian. $O$ perspectivã semiotică (Net, 2000), una aportación importante al pensamiento semiótico rumano de hoy y también a lo que podría ser la semioestilística.

Una característica de los signos poéticos es que existen de verdad en acto y que en su decodificación un papel importante lo tiene la relación con las convenciones de código, por tanto extralingüísticas, de la literatura, al igual que una conciencia semiótica valorizadora.

Es evidente que «el lenguaje aparece dividido en su foro interior entre la plenitud de un significado vivido como presencia y lo exhaus- 
tivo de un significado representado fuera de cualquier contenido intuitivo, entre poesía y lógica» (Dufrenne, 1975: 58), o, dicho de otra manera, entre los signos poéticos y los lingüísticos.

El mundo de la poesía se crea, a la vez, que los signos que lo instituyen. $Y$ entonces, en este caso, es menos importante el grado de similitud entre el mundo textual y el plano referencial, el tipo de mímesis (reproducción «ennoblecida», como en la poética clásica o transfiguración visionaria como en la poética moderna) o el hecho de que lo real es recreado siguiendo leyes inmanentes al poema, rechazando cualquier confrontación referencial. Como acto de figuración del mundo, la mímesis (con su variante anti-mimética) es en realidad un aspecto constitutivo de la semiosis en el texto poético, que precisamente por esta figuración solicita la interpretación; «la realidad», reconocible o no, está sometida, de todos modos, a la acción desviadora del poema como suspensión del referente real para hacer que exista el referente imaginario propuesto por el poeta.

Por consiguiente, lo importante es la modalidad de instauración a través de la palabra de la realidad aleatoria de la poética surrealista, de los fascículos de lo real y el comienzo de la productividad semiótica de las delimitaciones operadas. Además de la materia del mundo, a disposición del poeta se encuentra también la materia de la lengua, cuya institucionalización en las formas canónicas ofrecidas por los diccionarios es ignorada por la poesía. Además de la carga semiótica que el texto poético proyecta en sus palabras, lo que significa su alejamiento de los significados estándares acreditados, lo que implica una reorganización del plano del significado, hay también un desarrollo de la productividad del significante, en busca de los significados que «hablen» de su materialidad, por la actualización de las virtualidades «semánticas» inscritas en sus cualidades sensoriales.

Cuando los signos poéticos se desprenden del todo de su soporte, los signos lingüísticos, como por ejemplo las poesías de Nina Cassian, Lotopoeme, al orientar la atención exclusivamente hacia la sustancia sonora, porque el significado ha sido evacuado, no es tan importante si pueden ser nombrados formaciones preléxicas (Coteanu, 1994) o postléxicas (Manolescu, 1987); son formaciones deslexicalizadas, concentradas en la de-construcción de los signos lingüísticos, ilustración del gesto semiótico fundador de significación poética en su esencia. Son libres y, por lo tanto, están condenados a la auto-significación en el absoluto. 
Como en la pintura no-figurativa, la materialidad en sí, la de lo concreto textual, invade la escena del texto e invita a la conciencia semiotizadora del hombre y la cultural del lector de poesía a significar. Es la forma extrema, en la que los puntos de referencia eurísticos de la significación han sido anulados y en la que la ilimitación de la semiosis empuja a la semiosis misma hasta el límite donde se pulveriza dejando de existir.

Las experiencias postmodernas de los poetas de la generación del «80» son desde el punto de vista de la semiosis poética extremadamente interesantes. Pondremos un ejemplo de la creación de Florin Iaru, en la que el signo linguístico se convierte en signo poético; el signo poético aparece, no más allá del signo lingüístico sino en contra de éste. La semiosis poética se realiza con la colaboración de otro código semiótico, el visual.

El texto que sigue es un auténtico texto icónico:

$$
\begin{gathered}
\text { Iubito, primește acești } \\
\text { trandafiri galbeni ca } \\
\text { expresie a înal- } \\
\text { tei mele consi- } \\
\text { derațiuni } \\
\text { etc. } \text { etc. } \\
\text { etc. }{ }^{3}
\end{gathered}
$$

Lo real se recupera a través del espejo mimético del pictograma que funciona de modo antifrástico en relación con la significación propiamente dicha linguiística de los lexemas. Se realiza incluso un espacio lúdico de las delimitaciones que rompen la unidad del signo lingüístico para hacerlo entrar en el «dibujo» textual (como en los versos: tei mele consi-/deratiuni-).

Para el valor instaurador de los signos poéticos hay un hecho extremadamente importante: «Una barrera invisible separa el mundo-mundo de la lengua del mundo-no-mundo — de la poesía - (...) La similitud no debe situarnos en un error: ni la más descriptiva de las poesías describe

3 «Querida, recibe estas rosas amarillas en testimonio de mi más alta consideración etc. etc. etc.» 
algo exterior a ella; siempre los paisajes, el universo o el contenido del poema están separados por una ruptura de orden ontológico de los paisajes, del universo o del contenido de la realidad que nos rodea» (Manolescu, 1987: 103).

\section{Referencias bibliográficas}

Alonso, D. ([1950] 1997). Poezie spaniolă. Încercare de metodă și limite stilistice. Bucuresti: Univers. [En la traducción se ha utilizado el original español: Poesía española. Ensayo de métodos y límites estilísticos. Madrid: Gredos, 1971].

COHEN, J. (1966). Structure du langage poétique. Paris: Flammarion.

COSERIU, E. (1966). Teoría del lenguaje y lingüística general. Segunda edición. Madrid: Gredos,1969.

COTEANU, I. (1984). «Reconstruirea poetică a cuvîntului». Studii și cercetări lingvistice (SCL) XXXV, 4: 279-282.

Dufrenne, M. (1975). Poeticul. Bucuresti: Univers.

GANDON, F. (2001). «Le dernier Saussure. Double articulation, anagrammes, brahmanisme». Semiotica, volume 133, 1/4: 210-237.

LARThOMAS, P. (1998). Notions de stylistique générale. Paris: PUF.

Manolescu, N. (1987). Despre poezie. Bucuresti: Cartea Românească.

MolinIÉ, G. (1998). Sémiostylistique. Effets de l'art. Paris: PUF.

MuNTEANU, S. (1972). Stil și expresivitate poetică. București: Editura Stiințifică.

NET, M. (200̉0). Eminescu, altfel. Limbajul poetic eminescian. O perspectivă semiotică. București: Minerva.

NET, M. (2001). «Des accents symboliques chez Mihai Eminescu». En Eminescu 2000. Atti del Convegno Internazionale "Mihai Eminescu», Venezia 18-20 maggio 2000, 93-98. Iași: Editura Universitătii «Al. I. Cuza».

OANCEA, I. (1988). Istoria stilisticii românești. București: Editura științifică si enciclopedică.

- (1998). Semiostilistica. Timișoara: Excelsior.

PAVEL, Th. G. (dir.) (1997). Littérature, 105: «Questions de style».

STAROBINSKY, J. (1974). Les mots sous les mots. Les anagrammes de Ferdinand de Saussure. Paris: Gallimard.

VIANU, T. (1957). Problemele metaforei și alte studii de stilistică. București: ESPLA.

VlaD, C. (2000). Textul aisberg. Elemente de teorie și analiză. Cluj: Casa Cărții de Știință. 